OPEN ACCESS

Edited by: Hassane Zouhal,

University of Rennes 2 - Upper Brittany, France

Reviewed by:

Beat Knechtle,

University of Zurich, Switzerland

Maha Sellami,

University of Split, Croatia

*Correspondence:

Sébastien Ratel

sebastien.ratel@uca.fr

Specialty section: This article was submitted to

Exercise Physiology, a section of the journal

Frontiers in Physiology

Received: 26 February 2018 Accepted: 28 March 2018 Published: 24 April 2018

Citation: Birat A, Bourdier P, Piponnier E, Blazevich AJ, Maciejewski H, Duché $P$ and Ratel S (2018) Metabolic and Fatigue Profiles Are Comparable Between Prepubertal Children and

Well-Trained Adult Endurance Athletes. Front. Physiol. 9:387. doi: 10.3389/fphys.2018.00387

\section{Metabolic and Fatigue Profiles Are Comparable Between Prepubertal Children and Well-Trained Adult Endurance Athletes}

\author{
Anthony Birat ${ }^{1}$, Pierre Bourdier ${ }^{1}$, Enzo Piponnier ${ }^{1}$, Anthony J. Blazevich ${ }^{2}$, \\ Hugo Maciejewski ${ }^{3}$, Pascale Duché ${ }^{1}$ and Sébastien Ratel ${ }^{1 *}$ \\ ${ }^{1}$ AME2P, UFR STAPS, Clermont-Auvergne University, Clermont-Ferrand, France, ${ }^{2}$ Centre for Exercise and Sports Science \\ Research, School of Exercise and Health Sciences, Edith Cowan University, Joondalup, WA, Australia, ${ }^{3}$ French Rowing \\ Federation, Nogent-sur-Marne, France
}

The aim of this study was to determine whether prepubertal children are metabolically comparable to well-trained adult endurance athletes and if this translates into similar fatigue rates during high-intensity exercise in both populations. On two different occasions, 12 prepubertal boys (10.5 $\pm 1.1 \mathrm{y}), 12$ untrained men (21.2 $\pm 1.5 \mathrm{y})$, and 13 endurance male athletes ( $21.5 \pm 2.7 \mathrm{y}$ ) completed an incremental test to determine the power output at $\mathrm{VO}_{2 \max }\left(\mathrm{PVO}_{2 \max }\right)$ and a Wingate test to evaluate the maximal anaerobic power $\left(\mathrm{P}_{\max }\right)$ and relative decrement in power output (i.e., the fatigue index, $\mathrm{FI})$. Furthermore, oxygen uptake $\left(\mathrm{VO}_{2}\right)$, heart rate $(\mathrm{HR})$, and capillary blood lactate concentration ([La]) were measured to determine (i) the net aerobic contribution at 5-s intervals during the Wingate test, and (ii) the post-exercise recovery kinetics of $\mathrm{VO}_{2}, \mathrm{HR}$, and [La]. The $\mathrm{P}_{\max }$-to- $\mathrm{PVO}_{2 \max }$ ratio was not significantly different between children (1.9 $\pm 0.5)$ and endurance athletes $(2.1 \pm 0.2)$ but lower than untrained men $(3.2 \pm 0.3$, $p<0.001$ for both). The relative energy contribution derived from oxidative metabolism was also similar in children and endurance athletes but greater than untrained men over the second half of the Wingate test ( $p<0.001$ for both). Furthermore, the post-exercise recovery kinetics of $\mathrm{VO}_{2}, \mathrm{HR}$, and [La] in children and endurance athletes were faster than those of untrained men. Finally, FI was comparable between children and endurance athletes ( $-35.2 \pm 9.6$ vs. $-41.8 \pm 9.4 \%$, respectively) but lower than untrained men $(-51.8 \pm 4.1 \%, p<0.01)$. To conclude, prepubertal children were observed to be metabolically comparable to well-trained adult endurance athletes, and were thus less fatigable during high-intensity exercise than untrained adults.

Keywords: growth, aerobic metabolism, high-intensity exercise, young people, recovery

\section{INTRODUCTION}

It has been widely demonstrated that prepubertal children fatigue less than untrained adults when performing dynamic, whole-body activities such as maximal cycling (Ratel et al., 2002), short running bouts (Ratel et al., 2004), and vertical jumps (Lazaridis et al., 2018), or maximum voluntary contractions under isometric (Hatzikotoulas et al., 2014; Ratel et al., 2015) or isokinetic 
conditions (De Ste Croix et al., 2009). The lower fatigability in prepubertal children has been mainly attributed to a lower peripheral (i.e., muscular) fatigue compared to untrained adults, owing to their greater relative reliance on oxidative energy sources (Ratel et al., 2008; Tonson et al., 2010) and their potentially greater proportion of fatigue-resistant slow-twitch muscle fibers (Lexell et al., 1992). This specific metabolic profile in prepubertal children could lead to a lower accumulation of metabolic by-products (e.g., $\mathrm{H}^{+}$ions and inorganic phosphate) and a lower phosphocreatine depletion during high-intensity exercise in prepubertal children compared to untrained adults (Kappenstein et al., 2013). As these metabolic by-products promote the development of peripheral fatigue through an alteration of contractile properties and reduction in excitationcontraction coupling (Allen et al., 2008), a lower accumulation of metabolites could translate into a reduced fatigue at the periphery, as usually observed in prepubertal children (Hatzikotoulas et al., 2014; Ratel et al., 2015).

Beyond muscular factors, prepubertal children also display faster $\mathrm{O}_{2}$ uptake and heart rate (HR) recovery kinetics following high-intensity exercise than untrained adults (Armon et al., 1991; Hebestreit et al., 1993). This could be ascribed to their lower anaerobic capacity and thus to their smaller $\mathrm{O}_{2}$ deficit incurred at the start of the exercise, which calls for a lesser excess postexercise $\mathrm{O}_{2}$ consumption. Furthermore, prepubertal children could be characterized by a greater parasympathetic reactivation of the autonomic nervous system early in the recovery period after exercise than untrained adults (Ohuchi et al., 2000). Taken together, this could explain why prepubertal children are able to complete repeated high-intensity exercise bouts easier when compared to their older untrained counterparts (Ratel et al., 2002, 2004).

However, it is now known that metabolic profiles show significant inter-individual variability in young adults, and is specifically associated with their training background. While adults with a strong sprint training background predominantly rely on anaerobic energy support during exercise, endurance athletes depend more notably on oxidative energy pathways than either untrained adults or sprint-trained athletes (Pesta et al., 2013). This more oxidative profile in endurance athletes translates particularly into (i) a faster recovery of power output (Bogdanis et al., 1995) and cardio-respiratory parameters following high-intensity exercise (Short and Sedlock, 1997) and (ii) a lower peripheral fatigue during repeated maximum voluntary contractions (Garrandes et al., 2007). Hence, it is possible that metabolic and fatigue profiles of well-trained adult endurance athletes could be similar to those observed in prepubertal children during high-intensity exercise, as previously stated by Ratel and Blazevich (2017). However, agreement has not been reached because there is a lack of scientific evidence relating to this issue.

Therefore, the aim of the present study was to determine whether, contrary to untrained adults, prepubertal children are metabolically comparable to well-trained adult endurance athletes and if this translates into similar fatigue rates during high-intensity exercise in both populations. We hypothesized that the relative energy contribution derived from oxidative metabolism during high-intensity exercise would be similar in prepubertal children and endurance-trained adult athletes, and this could lead to comparable fatigue rates between both populations. Furthermore, it is presumed that untrained adults rely less on oxidative metabolism and therefore fatigue faster during high-intensity exercise than prepubertal children and well-trained adult endurance athletes.

\section{MATERIALS AND METHODS}

\section{Participants}

Twelve healthy boys (age: 8-12 y), 12 untrained men (19-23 y), and 13 endurance male athletes (19-27 y) volunteered to participate in the study. To be included, boys and untrained men had to perform recreational physical activity for $\leq 4 \mathrm{~h}$ per week and to be free of any medical contra-indication to physical activity. Boys were prepubertal based on the assessment of their somatic maturity (see below). None of them were involved in any vigorous physical activity or engaged in a specific aerobic training program. Boys were recruited from primary and secondary schools while untrained men were university students. Their recreational physical activities were Alpine skiing, snowboarding, sailing, skateboarding, climbing, etc. In contrast, endurancetrained adults were engaged in long distance physical activities for $\geq 6$ times a week for at least 2 years and were nationallevel competitive athletes (i.e., long-distance runners, cyclists, and triathletes). They were recruited from local sports clubs (athletics, triathlon, and cycling). This study was approved by a local Institutional Ethics Review Board. The study was conducted in conformity with the policy statement regarding the use of human subjects by the Declaration of Helsinki. All experimental procedures were clearly explained to the participants, who then gave written consent before the commencement of testing. Written consent was also obtained from parents/guardians before children were accepted into the study.

\section{Experimental Procedure (Design)}

All participants were tested in two experimental sessions separated by at least $48 \mathrm{~h}$. During the first experimental session, anthropometric characteristics, body composition, maturation status, and the power at maximum $\mathrm{O}_{2}$ uptake $\left(\mathrm{PVO}_{2 \max }\right)$ were evaluated. Furthermore, the participants had to perform two sprints $(\sim 7 \mathrm{~s})$ on a cycle ergometer (Cyclus model II, MSE Electronic Medical, Leipzig, Germany) separated by 1 min of recovery against a resistance corresponding to $7.5 \%$ body mass (BM). These sprints served to familiarize the volunteers with the experimental procedures of the second session. During the second visit, the participants were asked to perform a Wingate cycle test to determine the maximal anaerobic power $\left(\mathrm{P}_{\max }\right)$, the fatigue rate (i.e., the relative decrement in power output), the relative (net) energy contribution derived from oxidative metabolism and the post-exercise recovery rates of blood lactate concentration, $\mathrm{HR}$, and $\mathrm{O}_{2}$ uptake. The Wingate cycle test was chosen because it allows the simultaneous investigation of cardiorespiratory, metabolic, and muscular components of fatigue during a whole-body dynamic activity and is a common and welllearned activity within the population. Furthermore, the Wingate 
cycle test was found to be highly reliable from one session to another in children and adults for the evaluation of high-intensity exercise performance indices (Hebestreit et al., 1993).

\section{Anthropometric Measurements and Body Composition Analysis}

Body mass was measured to the nearest $0.1 \mathrm{~kg}$ using a digital weight scale (TANITA, BC-545N, Japan) and standing height was assessed using a portable stadiometer with the participants barefoot (TANITA, HR001, Japan). Sitting height was also measured with the stadiometer while the participants sat on the floor with their back against a wall. Body Mass Index (BMI) was subsequently calculated by the equation BM $(\mathrm{kg}) /$ height ${ }^{2}\left(\mathrm{~m}^{2}\right)$. Skinfold thickness was measured in duplicate at the triceps and subscapular sites using a Harpenden caliper (Baty International, Burgess Hill, UK). The measurements were taken by the same investigator on the right side of the body to reduce variability in the results. Body fat (BF, \%) was assessed using Slaughter's equations (Slaughter et al., 1988). Body fat (kg) was calculated by multiplying BF (\%) by BM (kg). Fat-free mass (FFM, kg) was determined by subtracting BF $(\mathrm{kg})$ from BM $(\mathrm{kg})$.

\section{Maturation Assessment}

Age from peak height velocity (APHV) was used to assess somatic maturity and determined by using height, sitting height and BM. Its calculation was only done in children and was based on sexspecific regression equations according to the method proposed by Mirwald et al. (2002).

\section{Maximal Aerobic Power Assessment}

$\mathrm{PVO}_{2 \max }$ was assessed using a submaximal graded test on a cycle ergometer (Cyclus model II, MSE Electronic Medical, Leipzig, Germany). Workloads were initially set at 30,100, and $130 \mathrm{~W}$ and then increased by 15,30 , and $30 \mathrm{~W}$ every $3 \mathrm{~min}$ in prepubertal children, untrained adults, and well-trained adult endurance athletes, respectively. The pedaling rate was constant and selfselected by the participants between 50 and $90 \mathrm{rpm}$. The test was designed to have one warm-up stage and three to four additional submaximal stages leading HR to at least $160 \mathrm{bpm}$. HR was measured during the last minute of each stage using the Polar recorder linked to the cycle ergometer (Polar Electro, Kempele, Finland). If the participant's HR did not reach a plateau or the participant did not maintain cadence, the measurement was considered to be invalid. $\mathrm{PVO}_{2 \max }$ was then assessed from individual linear regressions between power output and HR and by calculating the power output at the age-predicted maximal $\mathrm{HR}$ $\left(\mathrm{HR}_{\max }\right)$. The squared Bravais-Pearson correlation coefficients of these linear relationships ranged between 0.91 and 0.99 (mean $\pm \mathrm{SD}: 0.98 \pm 0.02$ ). $\mathrm{HR}_{\max }$ was assessed using the equation formulated by Shargal et al. (2015), which was validated from a large cohort of healthy males aged between 10 and 80 years:

$$
\mathrm{HR}_{\max }=208.609-0.716 \times \text { age }
$$

Furthermore, $\mathrm{VO}_{2 \max }$ was assessed using the following equation:

$$
\mathrm{VO}_{2 \max }\left(\mathrm{L} \cdot \min ^{-1}\right)=\left(\mathrm{PVO}_{2 \max }(\mathrm{W}) \times 60\right) /(\mathrm{E} \times \mathrm{R})
$$

where $E$ is the caloric equivalent of oxygen for a respiratory exchange ratio above 1.0 , i.e., $21131 \mathrm{~J} \cdot \mathrm{L}^{-1}$, and $R$ the cycling efficiency (\%). A delta efficiency of $23 \%$ was chosen for all the volunteers since the literature reports no apparent difference during cycling between 10.5-year-old boys (23.2\%), 21.3-yearold untrained men (22.5\%), and 25.6-year-old well-trained endurance triathletes and cyclists (22.7\%) (Rowland et al., 1990; Louis et al., 2012).

\section{The Fatigue Protocol}

The testing session started with a rest period of $10 \mathrm{~min}$ in a sitting position on the cycle ergometer. The saddle height was set at $107 \%$ of trochanteric leg length to give optimal comfort to each participant (Hamley and Thomas, 1967). Afterwards, the participants were asked to perform a standardized warmup of 4 min cycling against a resistance that was adjusted to $2 \%$ of their BM. At the end of the second, third, and fourth minutes, they also had to perform one sprint lasting $5 \mathrm{~s}$ against a resistance corresponding to $7.5 \%$ BM. After a subsequent 5min rest, the participants were instructed to perform a Wingate test that consisted of pedaling as fast as possible for $30 \mathrm{~s}$ against a resistance corresponding to $0.075 \mathrm{~g} \cdot \mathrm{kg}^{-1} \mathrm{BM}$ (BarOr, 1987). This braking load was chosen as it does not appear to influence $\mathrm{P}_{\max }$ or fatigue rate during the Wingate test, when compared to heavier loads (e.g., 11\% BM), in either untrained adults or less-powerful athletes such as endurance athletes (Jaafar et al., 2016). Furthermore, it corresponds to an optimal braking load to produce $\mathrm{P}_{\max }$ and mean power output $\left(\mathrm{P}_{\text {mean }}\right)$ during a Wingate test in children aged from 6 to 12 years (Carlson and Naughton, 1994). Prior to each sprint, the experimenter announced a countdown of "5-4-3-2-1-GO" during which the participants were instructed to put the right crank arm $45^{\circ}$ past top position. After test termination, the subjects were supervised during a 20 -min recovery period in a sitting position. The participants were instructed not to engage in any strenuous activity on the day preceding the exercise test.

\section{Ratings of Perceived Exertion}

Ratings of perceived exertion (RPE) were noted immediately after completion of the Wingate test using the Children's Effort Rating Table (Williams et al., 1994). The Children's Effort Rating Table (CERT) asks participants to rate their effort on a 1-10 scale with 1 indicating that the exercise is very, very easy, and 10 indicating that the effort is so hard that the participant has to stop. Before testing, the range of sensations that correspond to categories of effort within the scale were clearly explained to each participant.

\section{Blood Sampling and Analysis}

Capillary blood samples $(0.2 \mu \mathrm{L})$ were obtained from the fingertips prior to the warm-up ([La $\left.]_{\text {rest }}\right)$, before the Wingate test, immediately after completion of the test $\left([\mathrm{La}]_{(0)}\right)$, and at 1, 3, 5, 7, 9,15 , and $20 \mathrm{~min}$ in recovery. Blood lactate concentrations were determined using the Lactate Scout ${ }^{+}$analyzer (EKF Diagnostic, Leipzig, Germany). The device was systematically calibrated before each experimental session. 


\section{Gas Exchange and HR Recording}

During the second experimental session, HR was continuously monitored using the Polar recorder linked to the Cyclus Model II ergometer (Polar Electro, Kempele, Finland). $\mathrm{VO}_{2}$ was also continuously measured breath-by-breath using a mobile spiroergometry system (METAMAX ${ }^{\circledR} 3 B$, CORTEX Biophysik GmbH, Leipzig, Germany).

\section{Data Processing}

\section{Power and Fatigue Indices}

Maximal anaerobic power $\left(\mathrm{P}_{\max }\right)$ and minimal power $\left(\mathrm{P}_{\min }\right)$ reached during the Wingate test were defined as the highest and the lowest mechanical powers respectively, recorded over a 0.5 -s period. The average power was considered as the mean power output $\left(\mathrm{P}_{\text {mean }}\right)$ sustained over the whole 30 -s test. The fatigue index (FI) was calculated as the difference between $\mathrm{P}_{\max }$ and $\mathrm{P}_{\min }$ expressed as percentage of $\mathrm{P}_{\max }$ (BarOr, 1987). The maximum anaerobic-to-aerobic mechanical power ratio was calculated by normalizing the Wingate testderived $\mathrm{P}_{\max }$ to the estimated maximal aerobic power $\left(\mathrm{P}_{\max }{ }^{-}\right.$ to- $\mathrm{PVO}_{2 \max }$ ratio). This anaerobic-to-aerobic power ratio was introduced by Bar-Or (1986) as a simple metabolic index to assess physiological function. A higher power ratio indicates a higher anaerobic ability relative to aerobic capacity. Several studies in adult elite athletes (cyclists and swimmers) have also demonstrated the usefulness of this mechanical power ratio in the physiological evaluation of these athletes, as the power ratio gives recommendations as to whether endurance training or specific strength and power training should be emphasized (Mercier et al., 1993; Baron, 2001).

\section{Relative Energy Contribution}

The aerobic energy (in J) utilized during the Wingate test was calculated at 5-s intervals based on the net oxygen uptake $\left(\mathrm{VO}_{2}-\mathrm{VO}_{2 \text { rest }}\right)$ and the caloric equivalent of oxygen for a respiratory exchange ratio above 1.0 , i.e., $21131 \mathrm{~J} \cdot \mathrm{mL}^{-1}$. The total energy consumed during the Wingate test was assessed from the mechanical work done at 5-s intervals and by considering a cycling efficiency of $23 \%$ for all the volunteers (Rowland et al., 1990; Louis et al., 2012). The relative energy contribution (\%) derived from aerobic metabolism was then calculated at 5-s intervals throughout the Wingate test.

\section{$\mathrm{HR}$ and $\mathrm{VO}_{2}$ Recovery Kinetics}

Resting $\mathrm{VO}_{2}$ and $\mathrm{HR}$ values ( $\mathrm{VO}_{2 \text { rest }}$ and $\mathrm{HR}_{\text {rest }}$, respectively) were determined in a sitting position during the first $10 \mathrm{~min}$ of the second experimental session. Furthermore, the peak values of $\mathrm{VO}_{2}$ and $\mathrm{HR}\left(\mathrm{VO}_{2 \mathrm{pk}}\right.$ and $\mathrm{HR}_{\mathrm{pk}}$, respectively) were considered as the highest values reached at the end of the Wingate test. As resting and peak values of $\mathrm{VO}_{2}$ and/or $\mathrm{HR}$ differed between groups, the post-exercise recovery kinetics of $\mathrm{VO}_{2}$ and $\mathrm{HR}$ were determined by considering the net changes (peak exercisebaseline) expressed as percentage of peak values. Subsequent comparisons were done from values taken at 15 -s intervals during the first 2-min and at 60-s intervals during the last 8-min. Values were more frequently taken at first in consideration of the initial fast phase of recovery of $\mathrm{VO}_{2}$ and $\mathrm{HR}$ in subsequent comparisons between groups.

\section{[La] Recovery Curves}

Individual blood lactate recovery curves were fitted to the biexponential time function:

$$
[\mathrm{La}](\mathrm{t})=[\mathrm{La}]_{(0)}+\mathrm{A}_{1}\left(1-\mathrm{e}^{-\gamma}{ }_{1} \mathrm{t}\right)+\mathrm{A}_{2}\left(1-\mathrm{e}^{-\gamma}{ }_{2} \mathrm{t}\right)
$$

where $[\mathrm{La}]_{(0)}$ and $[\mathrm{La}](t)\left(\mathrm{mmol} \cdot \mathrm{L}^{-1}\right)$ are lactate concentrations in capillary blood measured at recovery onset and at a given recovery time, respectively; concentration parameters $A_{1}$ and $A_{2}$ (mmol. $\mathrm{L}^{-1}$ ) are the amplitudes of the exponential functions, and $\gamma_{1}$ and $\gamma_{2}\left(\mathrm{~min}^{-1}\right)$ are the velocity constants that describe lactate exchange and removal capacity, respectively (Zouloumian and Freund, 1981). The blood lactate recovery curves were fitted to eq. 3 by iterative nonlinear regression using the GraphPad Prism 7 software (La Jolla, California, USA) to determine the values of $\mathrm{A}_{1}, \mathrm{~A}_{2}, \gamma_{1}$, and $\gamma_{2} ;[\mathrm{La}]_{(0)}$ being an experimental measurement. Furthermore, the highest blood lactate concentration reached during the post-exercise recovery period $\left([\mathrm{La}]_{\mathrm{pk}}\right)$ and the time required to reach $[\mathrm{La}]_{\mathrm{pk}}\left(t[\mathrm{La}]_{\mathrm{pk}}\right)$ were calculated from individual blood lactate recovery curves. Equation (3) was considered representative of lactate recovery kinetics since it accounted for more than $96 \%$ of the variance in the experimental blood lactate recovery curves $(0.965<r<0.998)$.

\section{Statistical Analysis}

Data were screened for normality of distribution and homogeneity of variances using a Shapiro-Wilk normality test and the Barlett's test, respectively. One-way (group) ANOVA was used to compare age, anthropometric characteristics, performance outcomes (e.g., $\mathrm{P}_{\max }, \mathrm{PVO}_{2 \max }, \mathrm{P}_{\max }$-to- $\mathrm{PVO}_{2 \max }$ ratio) and blood lactate kinetics parameters (e.g., $A_{1}, A_{2}, \gamma_{1}$, $\left.\left.\gamma_{2}, \mathrm{La}\right]_{\mathrm{pk}}, t \mathrm{La}\right]_{\mathrm{pk}}$ ) between groups. When ANOVA revealed a significant effect, a Newman-Keuls post-hoc test was applied to test the discrimination between means. Furthermore, a two-way (group $\times$ time) ANOVA with repeated measures was used to analyze the relative energy contribution from oxidative metabolism throughout the Wingate test as well as the postexercise recovery kinetics of $\mathrm{HR}$ and $\mathrm{O}_{2}$ uptake. When ANOVA revealed a significant main or interaction effect, a NewmanKeuls post-hoc test was applied to test the discrimination between means. The size effect and statistical power have also been reported when significant main or interaction effects were detected. The size effect was assessed using the partial eta-squared $\left(\eta^{2}\right)$ and ranked as follows: $\sim 0.01=$ small effect, $\sim 0.06=$ moderate effect, $\geq 0.14=$ large effect (Cohen, 1969). A linear regression model between the fatigue index and the $\mathrm{P}_{\max }$-to- $\mathrm{PVO}_{2 \max }$ ratio was fitted by the least squares method considering all the volunteers, and a squared Bravais-Pearson correlation coefficient $\left(r^{2}\right)$ of this linear regression model was calculated. The limit for statistical significance was set at $p<0.05$. Statistical procedures were performed using Statistica 8.0 software (Statsoft, Inc., USA). Results were presented in the text, tables and figures as mean $\pm \mathrm{SD}$. 


\section{RESULTS}

\section{Participants' Physical Characteristics}

The physical characteristics of participants are presented in Table 1. ANOVA revealed significant differences between the different groups for age $\left[F_{(2,34)}=131.1, p<0.001, \eta^{2}=0.88\right.$, power $=1.0]$, height $\left[F_{(2,34)}=110.2, p<0.001, \eta^{2}=0.87\right.$, power $=1.0]$, $\mathrm{BM}\left[F_{(2,34)}=123.2, p<0.001, \eta^{2}=0.88\right.$, power $=$ $1.0]$, BMI $\left[F_{(2,34)}=61.2, p<0.001, \eta^{2}=0.78\right.$, power $\left.=1.0\right]$, $\mathrm{BF}(\%)\left[F_{(2,34)}=20.4, p<0.001, \eta^{2}=0.55\right.$, power $\left.=0.99\right]$, $\operatorname{FFM}(\mathrm{kg})\left[F_{(2,34)}=183.8, p<0.001, \eta^{2}=0.92\right.$, power $\left.=1.0\right]$, $\mathrm{HR}_{\text {rest }}\left[F_{(2,34)}=33.6, p<0.001, \eta^{2}=0.66\right.$, power $\left.=1.0\right]$, $\mathrm{PVO}_{2 \max }(\mathrm{W})\left[F_{(2,34)}=118.4, p<0.001, \eta^{2}=0.87\right.$, power $=$ 1.0], $\mathrm{PVO}_{2 \max } / \mathrm{BM}\left(\mathrm{W} \cdot \mathrm{kg}^{-1}\right)\left[F_{(2,34}\right)=26.1, p<0.001, \eta^{2}=$ 0.61 , power $=0.99]$, and the $\mathrm{P}_{\max }$-to- $\mathrm{PVO}_{2 \max }$ ratio $\left[F_{(2,34)}=\right.$ $38.5, p<0.001, \eta^{2}=0.69$, power $\left.=1.0\right]$. Post-hoc tests showed no significant difference for age and height between untrained adults and well-trained adult endurance athletes. However, untrained adults displayed significantly higher values for BM $(p<0.05)$, BMI $(p<0.01)$, BF $(p<0.05)$, FFM $(p<0.05)$, HR rest $(p<0.001)$ when compared to their well-trained endurance counterparts. In contrast, as expected, $\mathrm{PVO}_{2 \max }\left(\mathrm{W}\right.$ and $\mathrm{W} \cdot \mathrm{kg}^{-1}$ ) was significantly higher in well-trained adult endurance athletes than untrained adults ( $p<0.001$ for both).

Furthermore, stature, BM, BMI, FFM, and $\mathrm{PVO}_{2 \max }(\mathrm{W})$ were significantly lower in prepubertal children than untrained adults and well-trained adult endurance athletes $(p<0.001$ for each). In contrast, prepubertal children displayed significantly higher values for $\mathrm{BF}$ and $\mathrm{HR}_{\text {rest }}$ than their older trained and untrained counterparts $(p<0.05$ at least). However, $\mathrm{PVO}_{2 \max } / \mathrm{BM}\left(\mathrm{W} \cdot \mathrm{kg}^{-1}\right)$ was not significantly different between prepubertal children and untrained adults.

TABLE 1 | Participants' physical characteristics.

\begin{tabular}{|c|c|c|c|}
\hline & $\begin{array}{c}\text { C } \\
n=12\end{array}$ & $\begin{array}{c}\text { EA } \\
n=13\end{array}$ & $\begin{array}{c}\text { UA } \\
n=12\end{array}$ \\
\hline Age $(y)$ & $10.5 \pm 1.1$ & $21.5 \pm 2.7^{\star \star \star \star}$ & $21.2 \pm 1.5^{\star \star \star}$ \\
\hline Years to (from) APHV & $-3.2 \pm 1.0$ & - & - \\
\hline Height (cm) & $141.6 \pm 7.5$ & $177.4 \pm 7.5^{\star \star \star}$ & $178.3 \pm 5.6^{\star \star \star}$ \\
\hline $\mathrm{BM}\left(\mathrm{kg} \cdot \mathrm{m}^{-2}\right)$ & $32.9 \pm 5.1$ & $67.5 \pm 7.0^{\star \star \star}$ & $75.3 \pm 8.7^{\star \star \star \$}$ \\
\hline $\mathrm{BMI}\left(\mathrm{kg} \cdot \mathrm{m}^{-2}\right)$ & $16.3 \pm 1.1$ & $21.4 \pm 1.5^{\star \star \star}$ & $23.7 \pm 2.3^{\star \star \star \$} \$$ \\
\hline $\mathrm{BF}(\%)$ & $16.4 \pm 2.9$ & $8.7 \pm 2.0^{\star \star \star}$ & $11.3 \pm 4.0^{\star \star \star \$}$ \\
\hline FFM (kg) & $27.5 \pm 4.2$ & $61.6 \pm 6.0^{\star \star \star}$ & $66.6 \pm 5.9^{\star \star \star \$}$ \\
\hline $\mathrm{HR}_{\text {rest }}(\mathrm{bpm})$ & $81.8 \pm 8.6$ & $53.2 \pm 7.5^{\star \star \star}$ & $72.7 \pm 10.6^{\star \star \star \$ \$ \$}$ \\
\hline $\begin{array}{l}\mathrm{VO}_{2 \max } / \mathrm{BM} \\
\left(\mathrm{mL} \cdot \mathrm{min}^{-1} \cdot \mathrm{kg}^{-1}\right)\end{array}$ & $49.0 \pm 7.9$ & $67.1 \pm 6.9^{\star \star \star}$ & $48.1 \pm 7.7^{\$ \$ \$}$ \\
\hline $\mathrm{PVO}_{2 \max }(\mathrm{W})$ & $130.2 \pm 26.9$ & $366.2 \pm 46.3^{\star \star \star}$ & $290.5 \pm 40.2^{\star \star \star} \$ \$ \$$ \\
\hline $\mathrm{PVO}_{2 \max } / \mathrm{BM}\left(\mathrm{W} \cdot \mathrm{kg}^{-1}\right)$ & $4.0 \pm 0.6$ & $5.4 \pm 0.6^{\star \star \star}$ & $3.9 \pm 0.6^{\$ \$ \$}$ \\
\hline$P_{\max }$-to- $\mathrm{PVO}_{2 \max }$ ratio & $1.9 \pm 0.5$ & $2.1 \pm 0.2$ & $3.2 \pm 0.3^{\star \star \star} \$ \$ \$$ \\
\hline
\end{tabular}

Values are means $\pm S D$. C, children; EA, endurance athletes; UA, untrained adults. * ${ }^{* *}$, ${ }^{\star * \star}$ Significantly different from children at $p<0.05, p<0.01$ and $p<0.001$, respectively. $\$, \$ \$ \$ \$$ Significantly different from endurance athletes (EA) at $p<0.05, p<0.01$ and $p<0.001$, respectively. APHV, age at the peak height velocity; BM, body mass; BMI, body mass index; $B F$, body fat; FFM, fat-free mass; $H R$, heart rate; $V O_{2 m a x}$, maximum oxygen uptake; $P \mathrm{VO}_{2 m a x}$, power at maximum oxygen uptake.
Interestingly, no significant difference was observed in the $\mathrm{P}_{\max }$-to- $\mathrm{PVO}_{2 \max }$ ratio between prepubertal children and well-trained adult endurance athletes; however, the $\mathrm{P}_{\max }$-to$\mathrm{PVO}_{2 \mathrm{max}}$ ratio was significantly higher in untrained adults than prepubertal children and well-trained adult endurance athletes $(p<0.001$ for both) (Table 1$)$.

\section{Exercise Period}

Performance outcomes obtained during the Wingate test are displayed in Figure 1 and Table 2. ANOVA revealed significant differences between the groups for $\mathrm{P}_{\max }(\mathrm{W})\left[F_{(2,34)}=178.8\right.$, $p<0.001, \eta^{2}=0.91$, power $\left.=1.0\right], \mathrm{P}_{\max } / \mathrm{BM}\left(\mathrm{W} \cdot \mathrm{kg}^{-1}\right)\left[F_{(2,34)}\right.$ $=49.6, p<0.001, \eta^{2}=0.74$, power $\left.=1.0\right], t \mathrm{P}_{\max }\left[F_{(2,34)}=\right.$ $12.4, p<0.001, \eta^{2}=0.42$, power $\left.=0.99\right], \mathrm{P}_{\text {mean }}(\mathrm{W})\left[F_{(2,34)}=\right.$ $201.4, p<0.001, \eta^{2}=0.92$, power $\left.=1.0\right], \mathrm{P}_{\text {mean }} / \mathrm{BM}\left(\mathrm{W} \cdot \mathrm{kg}^{-1}\right)$ $\left[F_{(2,34)}=46.9, p<0.001, \eta^{2}=0.73\right.$, power $\left.=1.0\right]$, FI $\left[F_{(2,34)}=\right.$ $12.6, p<0.01, \eta^{2}=0.43$, power $\left.=0.99\right]$, and $\operatorname{RPE}\left[F_{(2,34)}=3.7\right.$, $p<0.05, \eta^{2}=0.18$, power $\left.=0.64\right]$. In contrast, ANOVA showed no significant effect for $\mathrm{HR}_{\mathrm{pk}}$ between the groups.

More specifically, untrained adults displayed significantly higher values for $\mathrm{P}_{\max }(\mathrm{W}), \mathrm{P}_{\text {mean }}(\mathrm{W})$, and FI (\%) than welltrained adult endurance athletes $(p<0.05$ at least). However, $\mathrm{P}_{\text {max }} / \mathrm{BM}\left(\mathrm{W} \cdot \mathrm{kg}^{-1}\right), \mathrm{P}_{\text {mean }} / \mathrm{BM}\left(\mathrm{W} \cdot \mathrm{kg}^{-1}\right), \mathrm{tP}_{\text {max }}$, and RPE were not significantly different between untrained and endurance trained adults. Furthermore, children displayed significantly lower values than untrained and trained adults for all parameters investigated ( $p<0.05$ at least) except for FI (\%), which was similar to that of endurance-trained adults.

Regarding the relative aerobic contribution, ANOVA tended to show a group $\times$ time interaction effect $\left[F_{(10,170)}=3.86\right.$, $p=0.09, \eta^{2}=0.09$, power $\left.=0.78\right]$. The relative aerobic contribution increased progressively during the Wingate test whatever the group considered (Figure 2). However, this increment was not significantly different between prepubertal children and well-trained adult endurance athletes but significantly lower in untrained adults compared to prepubertal children over the second half of the Wingate test $(p<0.05$ at least). Furthermore, well-trained adult endurance athletes displayed a significantly greater relative aerobic contribution than untrained adults over the last $10 \mathrm{~s}$ of the Wingate test $(p<0.05)$.

\section{Post-exercise Recovery Period}

ANOVA revealed a significant group $\times$ time interaction throughout the post-exercise recovery period for $\mathrm{HR}$ $\left[F_{(32,544)}=11.71, p<0.001, \eta^{2}=0.41\right.$, power $\left.=1.0\right]$ and $\mathrm{VO}_{2}\left[F_{(32,480)}=2.24, p<0.001, \eta^{2}=0.13\right.$, power $=0.99]$. Post-hoc tests showed a faster recovery of $\mathrm{HR}$ in prepubertal children compared to trained adults from 45-s of recovery, and in prepubertal children compared to untrained adults from 30-s of recovery until the end of test. Furthermore, the recovery rate of HR was significantly faster in endurance-trained athletes compared to untrained adults between the first and second minutes of recovery (Figure 3).

No significant difference in the recovery rate of $\mathrm{VO}_{2}$ was observed between prepubertal children and well-trained adult 


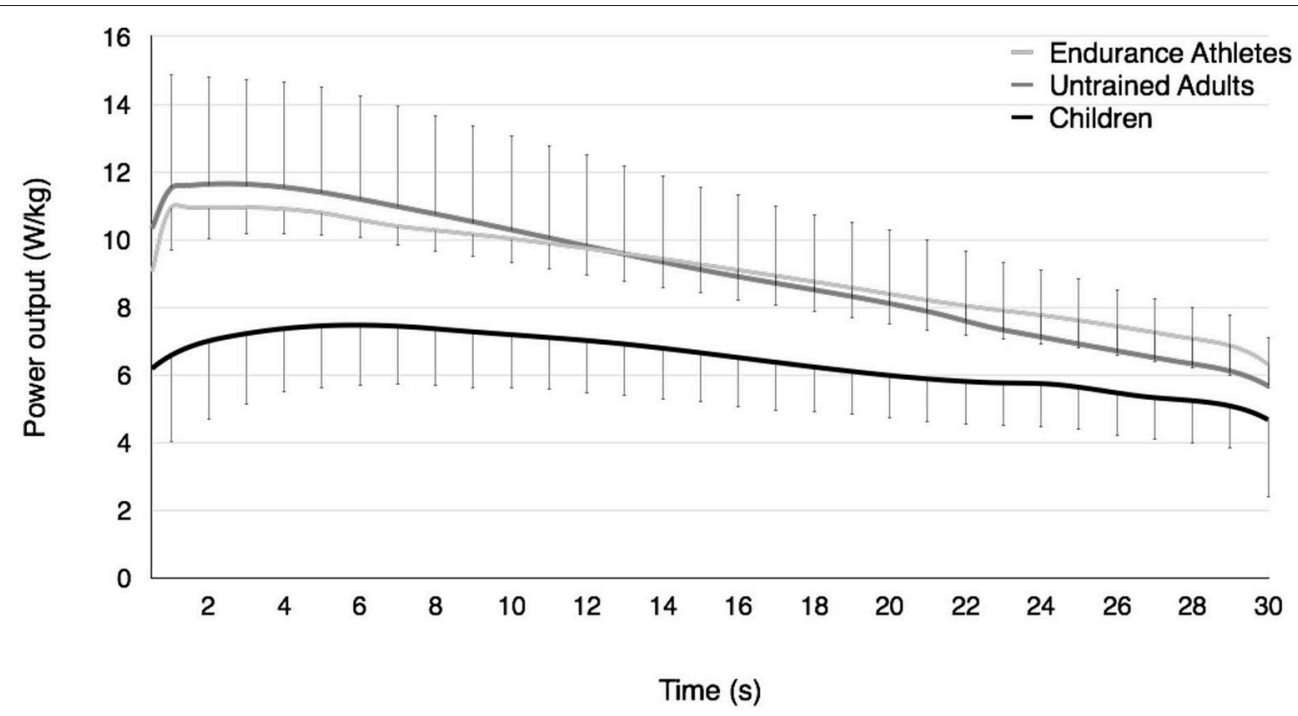

FIGURE 1 | Time course of power output during the Wingate test in prepubertal children, untrained adults, and well-trained adult endurance athletes. The relative decrement in power output (i.e., the fatigue index) is higher in untrained adults than children and well-trained adult endurance athletes but similar in children and well-trained adult endurance athletes.

TABLE 2 | Performance outcomes during the Wingate test in prepubertal children, untrained adults and well-trained adult endurance athletes.

\begin{tabular}{|c|c|c|c|}
\hline & $\begin{array}{c}\text { C } \\
n=12\end{array}$ & $\begin{array}{c}\text { EA } \\
n=13\end{array}$ & $\begin{array}{c}\text { UA } \\
n=12\end{array}$ \\
\hline \multicolumn{4}{|l|}{ POWER OUTPUT } \\
\hline$P_{\max }(\mathrm{W})$ & $247.5 \pm 74.1$ & $771.3 \pm 105.1^{\star \star \star}$ & $905.2 \pm 87.5^{\star \star \star \$ \$ \$}$ \\
\hline $\mathrm{P}_{\max } / \mathrm{BM}\left(\mathrm{W} \cdot \mathrm{kg}^{-1}\right)$ & $7.5 \pm 1.4$ & $11.4 \pm 1.0^{\star \star \star}$ & $12.1 \pm 1.3^{\star \star \star}$ \\
\hline $\mathrm{tP} \max (\mathrm{s})$ & $5.8 \pm 3.3$ & $1.9 \pm 1.6^{\star \star \star}$ & $1.8 \pm 1.6^{\star \star \star}$ \\
\hline$P_{\text {mean }}(\mathrm{W})$ & $207.1 \pm 44.5$ & $612.1 \pm 73.0^{\star \star \star}$ & $678.9 \pm 65.6^{\star \star \star \$}$ \\
\hline $\mathrm{P}_{\text {mean }} / \mathrm{BM}\left(\mathrm{W} \cdot \mathrm{kg}^{-1}\right)$ & $6.3 \pm 0.8$ & $9.1 \pm 0.7^{\star \star \star}$ & $9.1 \pm 0.9^{\star \star \star}$ \\
\hline $\mathrm{FI}(\%)$ & $35.2 \pm 9.6$ & $41.8 \pm 9.4$ & $51.8 \pm 4.1^{\star \star \star \$ \$}$ \\
\hline \multicolumn{4}{|c|}{ RATINGS OF PERCEIVED EXERTION } \\
\hline RPE (1-10 scale) & $7.5 \pm 1.0$ & $8.5 \pm 1.1^{\star}$ & $8.1 \pm 0.7^{\star}$ \\
\hline \multicolumn{4}{|l|}{ HEART RATE } \\
\hline $\mathrm{HR}_{\mathrm{pk}}(\mathrm{bpm})$ & $175.5 \pm 12.4$ & $166.6 \pm 13.0$ & $175.0 \pm 6.3$ \\
\hline
\end{tabular}

Values are means $\pm S D$. C,children; $E A$, endurance athletes; UA, untrained adults. ${ }^{*},{ }^{* *},{ }^{* * *}$ Significantly different from children at $p<0.05, p<0.01$, and $p<0.001$, respectively. $\$, \$ \$ \$ \$$ Significantly different from endurance athletes at $p<0.05, p<0.01$, and $p<0.001, B M$, body mass; $P_{\max }$, maximal anaerobic power; $t P_{\max }$, time required to reach; $P_{\max }, P_{\text {mean }}$, mean power output; Fl, Fatigue index; $R P E$, rating of perceived exertion; $H R_{p k}$, peak heart rate.

endurance athletes (Figure 4). However, $\mathrm{VO}_{2}$ recovered faster in prepubertal children and well-trained adult endurance athletes compared to untrained male adults between 45 and 120 -s of recovery.

Finally, ANOVA revealed a significant group effect for $[\mathrm{La}]_{(0)}$ $\left[F_{(2,34)}=5.85, p<0.01, \eta^{2}=0.26\right.$, power $\left.=0.84\right],[\mathrm{La}]_{\mathrm{pk}}\left[F_{(2,34)}\right.$ $=39.88, p<0.001, \eta^{2}=0.70$, power $\left.=1.0\right], t[\mathrm{La}]_{\mathrm{pk}}\left[F_{(2,34)}=\right.$ 4.81, $p<0.05, \eta^{2}=0.22$, power $\left.=0.76\right], \mathrm{A}_{1}\left[F_{(2,34)}=10.08\right.$, $p<0.001, \eta^{2}=0.37$, power $\left.=0.98\right], \mathrm{A}_{2}\left[F_{(2,34)}=17.8, \mathrm{p}<0.001\right.$, $\eta^{2}=0.51$, power $\left.=0.99\right]$, and $\gamma_{2}\left[F_{(2,34)}=14.31, p<0.001, \eta^{2}\right.$ $=0.46$, power $=0.99]$. In contrast, no significant group effect was observed for $[\mathrm{La}]_{\text {rest }}$ and $\gamma_{1}$ (Table 3). More specifically, $A_{1}$, $\mathrm{A}_{2}$, and $t[\mathrm{La}]_{\mathrm{pk}}$ were similar in untrained and trained adults but higher than prepubertal children ( $p<0.05$ at least). Furthermore, $\gamma_{2}$ and $[\mathrm{La}]_{\mathrm{pk}}$ were significantly different between groups $\left(\gamma_{2}\right.$ : children $>$ trained adults $>$ untrained adults; $[\mathrm{La}]_{\mathrm{pk}}$ : untrained adults $>$ trained adults $>$ children).

\section{Correlation}

A significant positive relationship was observed between FI (\%) and the $\mathrm{P}_{\max }$-to- $\mathrm{PVO}_{2 \max }$ ratio considering all participants $\left(r^{2}=0.54, p<0.001\right)$ (Figure 5).

\section{DISCUSSION}

The aim of the present study was to determine whether, contrary to untrained adults, prepubertal children are metabolically comparable to well-trained adult endurance athletes and if this translates into similar fatigue rates during high-intensity exercise between both populations. The main results confirm our hypotheses since prepubertal children had a comparable net contribution of energy derived from aerobic metabolism to well-trained adult endurance athletes, and the rate of fatigue, as illustrated by the relative decrement in power output during the Wingate test, was similar between both populations. Furthermore, the post-exercise recovery rates of oxygen uptake and HR were respectively similar and faster in prepubertal children than well-trained adult endurance athletes. The removal ability of lactate from the blood compartment was also higher in children than well-trained adult endurance athletes. 


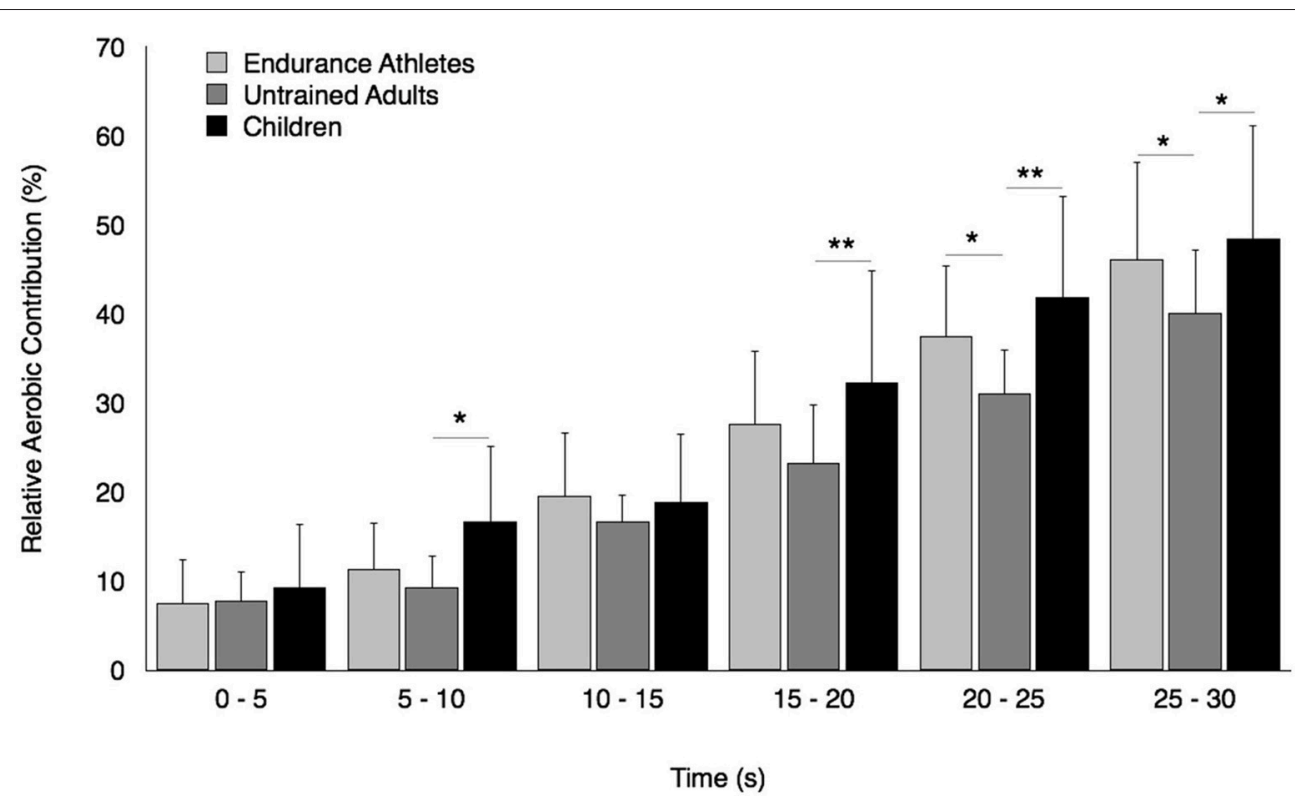

FIGURE 2 | Relative contribution of energy derived oxidative metabolism at 5-s intervals over the Wingate test in prepubertal children, untrained adults, and well-trained adult endurance athletes. *, **Significantly different at $p<0.05$ and $p<0.01$, respectively.

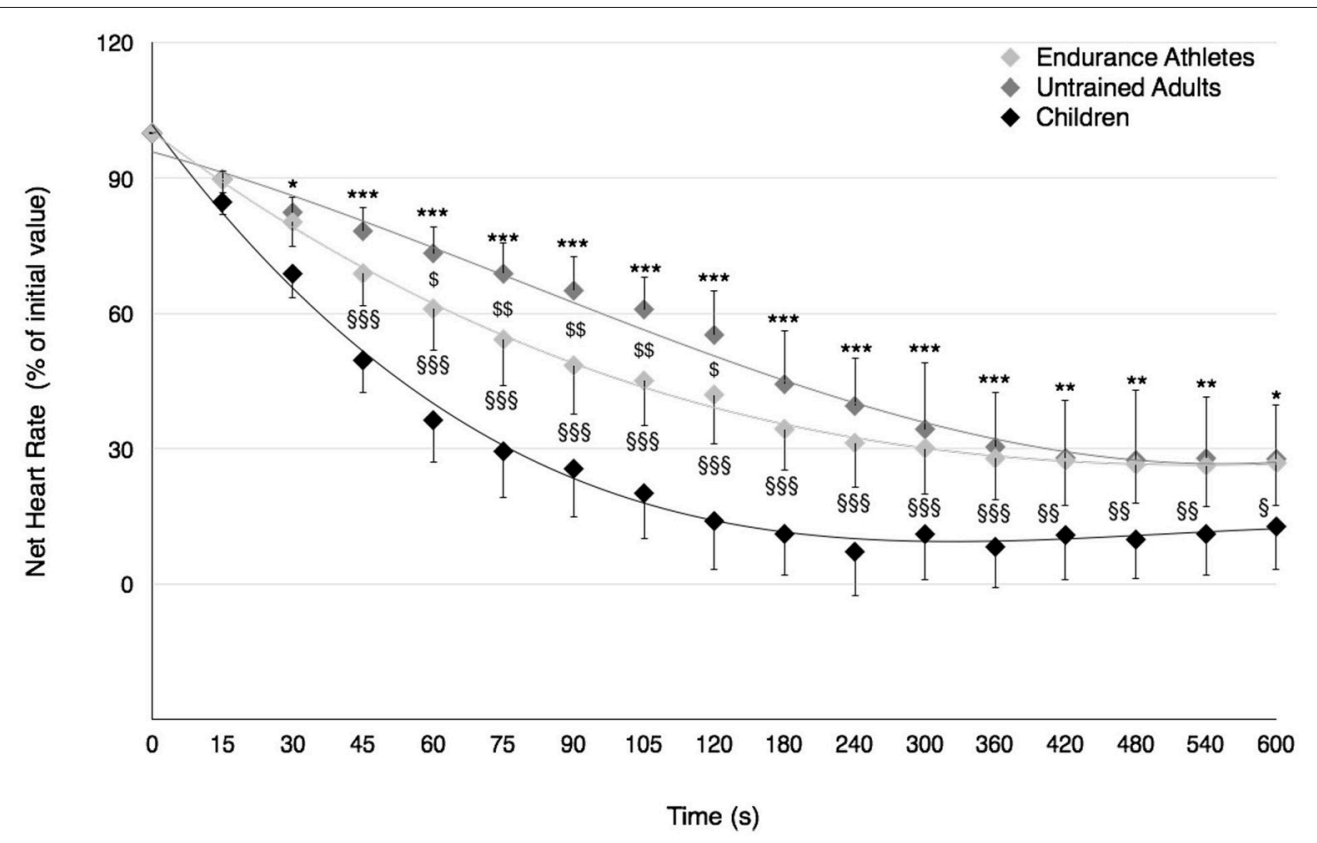

FIGURE 3 | Recovery of net heart rate after the Wingate test in prepubertal children, untrained adults, and well-trained adult endurance athletes. Values were expressed as percentage of initial values. ${ }^{*},{ }^{* \star},{ }^{* * *}$ Significantly different at $p<0.05, p<0.01$, and $p<0.001$, respectively, between children and untrained adults. $\$, \$ \$$ Significantly different at $p<0.05$ and $p<0.01$, respectively, between untrained adults and well-trained adult endurance athletes. $\$, \S \S, \S \S$ Significantly different at $p<0.05, p<0.01$, and $p<0.001$, respectively, between children and well-trained adult endurance athletes.

\section{Comparison Between Children and Untrained Adults}

In the present study, prepubertal children displayed a lower relative decrement in power output during the Wingate test than untrained adults ( -35.2 vs. $51.8 \%$, respectively); thus they fatigued much less than their untrained older counterparts. This finding cannot be explained by the fact that children performed more (especially aerobic) physical activity since the boys and men had to meet the same strict inclusion criteria and their relative $\mathrm{VO}_{2 \max }$ were not significantly different (49.0 vs. 


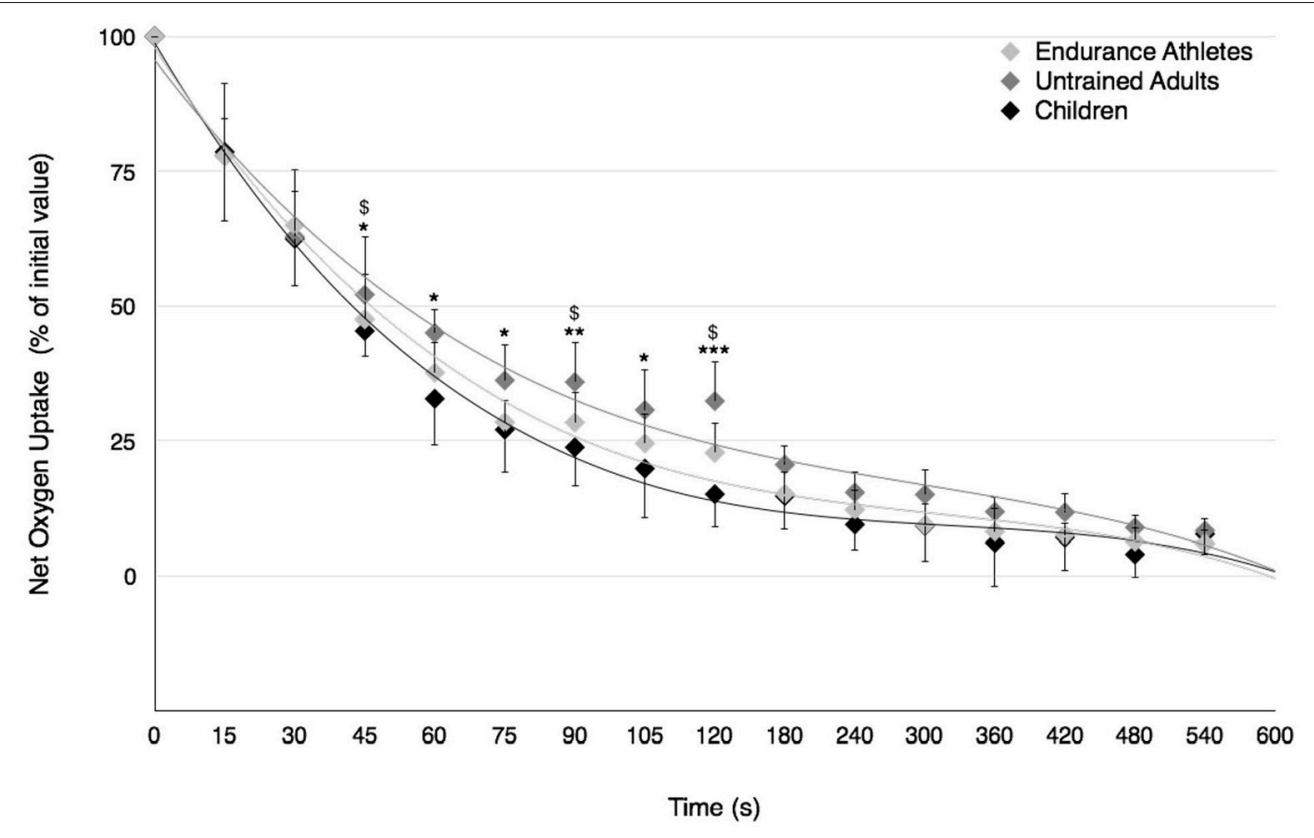

FIGURE 4 | Recovery of net $\mathrm{O}_{2}$ uptake after the Wingate test in prepubertal children, untrained adults and well-trained adult endurance athletes. Values were expressed as percentage of initial values. ${ }^{*},{ }^{* \star},{ }^{* \star *}$ Significantly different at $p<0.05, p<0.01$, and $p<0.001$, respectively, between children and untrained adults. $\$$ Significantly different at $p<0.05$ between untrained adults and well-trained adult endurance athletes.

TABLE 3 | Blood lactate kinetics parameters obtained during the recovery period of the Wingate test in prepubertal children, untrained adults and well-trained adult endurance athletes.

\begin{tabular}{lccc}
\hline & C & EA & UA \\
& $\boldsymbol{n}=\mathbf{1 2}$ & $\boldsymbol{n}=\mathbf{1 3}$ & $\boldsymbol{n}=\mathbf{1 2}$ \\
\hline$[\mathrm{La}]_{\mathrm{rest}}\left(\mathrm{mmol} \cdot \mathrm{L}^{-1}\right)$ & $1.8 \pm 0.6$ & $1.8 \pm 0.7$ & $2.0 \pm 0.7$ \\
{$[\mathrm{La}]_{(0)}\left(\mathrm{mmol} \cdot \mathrm{L}^{-1}\right)$} & $4.6 \pm 1.0$ & $5.3 \pm 1.8$ & $7.0 \pm 2.4^{\star \star \star} \$$ \\
$\mathrm{~A}_{1}\left(\mathrm{mmol}^{-1} \mathrm{~L}^{-1}\right)$ & $3.7 \pm 1.9$ & $8.9 \pm 4.7^{\star \star \star}$ & $8.9 \pm 2.3^{\star \star}$ \\
$\gamma_{1}\left(\mathrm{~min}^{-1}\right)$ & $0.78 \pm 0.33$ & $0.73 \pm 0.40$ & $0.86 \pm 0.39$ \\
$\mathrm{~A}_{2}\left(\mathrm{mmol}^{-1}\right)$ & $-7.5 \pm 2.2$ & $-13.6 \pm 4.9^{\star \star \star}$ & $-15.3 \pm 2.2^{\star \star \star}$ \\
$\gamma_{2}\left(\mathrm{~min}^{-1}\right)$ & $0.07 \pm 0.04$ & $0.04 \pm 0.01^{\star \star}$ & $0.02 \pm 0.01^{\star \star \star}, \$$ \\
{$[\mathrm{La}]_{\mathrm{pk}}\left(\mathrm{mmol} \cdot \mathrm{L}{ }^{-1}\right)$} & $6.6 \pm 2.1$ & $10.7 \pm 2.2^{\star \star \star}$ & $13.9 \pm 1.7^{\star \star \star}, \$ \$ \$$ \\
$t[\mathrm{La}]_{\mathrm{pk}}(\mathrm{min})$ & $2.5 \pm 1.1$ & $3.8 \pm 1.2^{\star}$ & $4.2 \pm 1.8^{\star}$ \\
\hline
\end{tabular}

Values are means $\pm S D$. C, children; EA, endurance athletes; UA, untrained adults. * **, ***: Significantly different from children at $p<0.05, p<0.01$, and $p<0.001$, respectively. $\$, \$ \$$ Significantly different from endurance athletes at $p<0.05$ and $p<0.001$, [La]rest, resting blood lactate concentration; $[\mathrm{La}]_{(0)}$, blood lactate concentration at end of exercise; $A_{1}$ and $A_{2}$ are the amplitudes of the exponential functions, respectively $\gamma_{1}$ and $\gamma_{2}$ are the velocity constants that describe lactate exchange and removal capacity, [La $]_{p k}$, peak blood lactate concentration; $t[\mathrm{La}]_{p k}$, time required to reach $[\mathrm{La}]_{p k}$.

$48.1 \mathrm{~mL} \cdot \mathrm{min}^{-1} \cdot \mathrm{kg}^{-1}$, respectively). The finding is in accordance with the literature showing a reduced susceptibility to fatigue in prepubertal children during different whole-body, high-intensity activities such as cycling (Ratel et al., 2002), running (Ratel et al., 2004), and hopping (Lazaridis et al., 2018), or during maximal voluntary contractions under isometric (Ratel et al., 2015) and isokinetic (De Ste Croix et al., 2009) conditions. The mechanisms underpinning the differences in fatigue between prepubertal

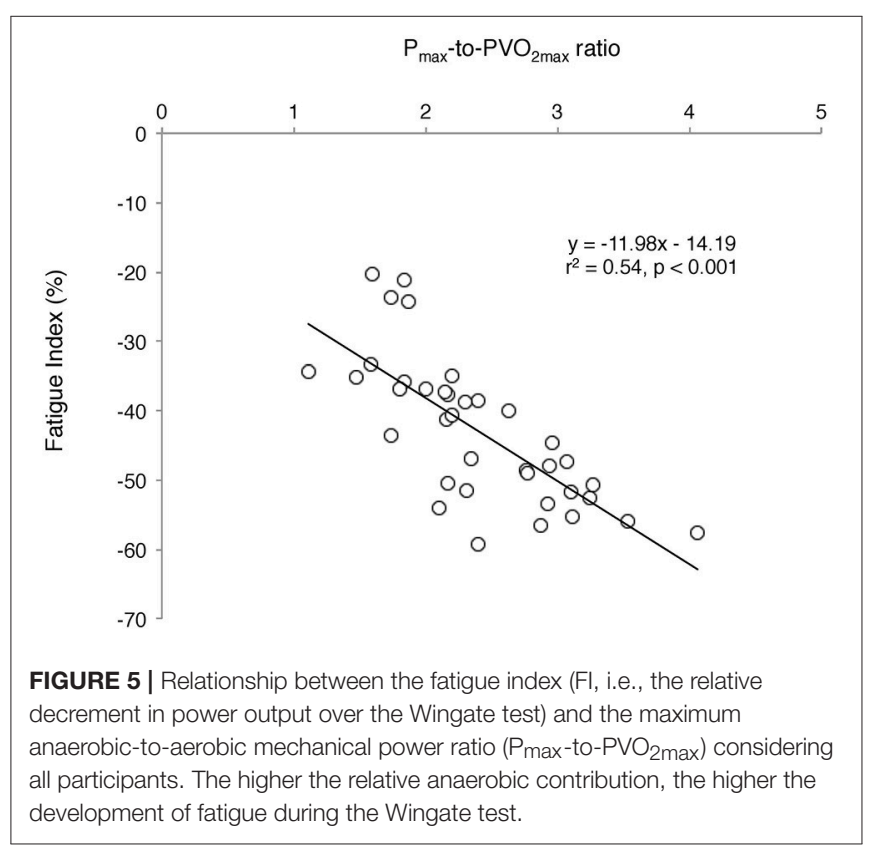

children and untrained adults are not yet fully understood but it appears that prepubertal children experience less peripheral (i.e., muscular) fatigue and potentially more central (i.e., neural) fatigue than untrained adults during high-intensity exercise (Streckis et al., 2007; Ratel et al., 2015). The greater fatigue effect on central mechanisms in prepubertal children could account for their lower fatigue at the peripheral level. Indeed, according 
to one theory, the central nervous system could limit the recruitment of motor units to prevent any extensive homeostasis disturbance, muscle damage, or biological harm (Noakes et al., 2005). However, direct evidence to support this assumption is still lacking. An alternative could be the lesser ability of prepubertal children to fully voluntarily activate motor units during highintensity exercise (Dotan et al., 2012). Indeed, a lower activation level was found to be associated with a higher resistance to fatigue in adults (Nordlund et al., 2004). In the present study, the maximal voluntary activation level was not measured; however, the longer lag time to reach maximal anaerobic power in children compared to untrained adults $\left(t \mathrm{P}_{\max }: 5.8\right.$ vs. $1.8 \mathrm{~s}$, respectively; e.g., Figure 1, solid black line) might be suggestive that the amplitude of muscle activation was lower during the early phase of the Wingate test in children and then increased over time, similar to wind-up effects observed in other (e.g., clinical) populations (Hornby et al., 2009). Therefore, the possibility exists that the higher resistance to fatigue in children could be also ascribed to an inability to fully activate the neuromuscular system during the early phase of an explosive exercise bout. This hypothesis should be explicitly examined in future studies.

Among peripheral factors, the greater relative contribution of energy derived from aerobic metabolism in prepubertal children may account for their lower fatigability during high-intensity exercise. The significant positive relationship found in the present study between the fatigue index and the $\mathrm{P}_{\max }$-to- $-\mathrm{PVO}_{2 \max }$ ratio as well as the lower $\mathrm{P}_{\max }$-to- $\mathrm{PVO}_{2 \max }$ ratio in children compared to young untrained adults ( $\sim 1.9$ vs. 3.2, respectively) support this assertion; the lower the relative anaerobic contribution, the lower the development of fatigue during high intensity exercise in children. Furthermore, the relative oxidative contribution was found to be greater in prepubertal children than untrained adults over the second half of the Wingate test. The recovery kinetics of cardio-respiratory parameters $\left(\mathrm{VO}_{2}\right.$ and $\left.\mathrm{HR}\right)$ and the removal ability of lactate out of the blood compartment $\left(\gamma_{2}\right)$ were also faster following the Wingate test in prepubertal children than untrained adults. These results are consistent with previous studies describing the changes in the anaerobic-toaerobic mechanical power ratio $\left(\mathrm{P}_{\max }-\right.$ to- $-\mathrm{PVO}_{2 \max }$ ratio $)$ during growth using either longitudinal (Falk and Bar-Or, 1993) or cross-sectional (Blimkie et al., 1986; Falgairette et al., 1991) experimental designs, despite aerobic mechanical power not being determined using direct $\mathrm{VO}_{2 \max }$ measurement in the current study. For instance, Falgairette et al. (1991) reported a progressive increment in the $\mathrm{P}_{\max }$-to- $-\mathrm{PVO}_{2 \max }$ ratio until the onset of adolescence (e.g., 1.8 at $9-10 \mathrm{y}, 2.2$ at $11-12 \mathrm{y}$, and 2.8 at $14-15$ y) in 144 boys, after which it remained stable until early adulthood ( $\sim 3.0$ in physically active but non-competitive young men in the study by Falk and Bar-Or, 1993). Furthermore, some authors have reported (i) a greater relative contribution of energy derived from oxidative metabolism during the Wingate test in 11.8-year-old boys than 16.3-year-old male adolescents (Beneke et al., 2007), and (ii) a smaller $\mathrm{O}_{2}$ deficit incurred at the start of cycle exercise at $125 \% \mathrm{VO}_{2 \max }$, which called for a lesser excess post-exercise $\mathrm{VO}_{2}$ in prepubertal children than untrained adults (Armon et al., 1991). Similarly, the recovery rate of HR was found to be faster in prepubertal children than untrained adults following high-intensity exercise lasting $1 \mathrm{~min}$ (Baraldi et al., 1991; Hebestreit et al., 1993). Our results are also consistent with the experimental data derived from blood measurements showing no difference in the exchange capacity of lactate from muscles into blood $\left(\gamma_{1}\right)$ between children and untrained adults but a better ability to remove lactate from the blood compartment $\left(\gamma_{2}\right)$ in children following the Wingate test (Beneke et al., 2005).

This more oxidative metabolic profile in prepubertal children is usually associated with a lesser accumulation of metabolic byproducts (i.e., $\mathrm{H}^{+}$ions, lactate, inorganic phosphate) derived from anaerobic sources in exercising muscle (Kappenstein et al., 2013). In the present study, lactate concentrations were only measured at the blood level, and the bi-exponential time function revealed a lower accumulation with a peak value appearing earlier during the post-exercise recovery period in prepubertal children, as evidenced by their lower $A_{1}, A_{2}$, and $[\mathrm{La}]_{\mathrm{pk}}$ values and shorter $t[\mathrm{La}]_{\mathrm{pk}}$ (Table 3). The underlying mechanisms of this diminished lactate response in prepubertal children has yet to be elucidated, but the pediatric literature often suggests that the lower blood/muscle lactate concentration in prepubertal children results from their lower glycolytic energy turnover (Ratel et al., 2002). Furthermore, it has been shown that the shorter $t[\mathrm{La}]_{\mathrm{pk}}$ in children could be related to their lower accumulated lactate rate during high intensity exercise (Dotan et al., 2003).

While lactate ion accumulation itself has only a small effect on the loss of muscle power in fatigue (Allen et al., 2008), the associated accumulation of metabolic by-products such as $\mathrm{H}^{+}$ions and inorganic phosphate could promote peripheral fatigue to a greater extent through an alteration of contractile processes and the excitation-contraction coupling (Allen et al., 2008). The lesser accumulation of these metabolites in children could therefore translate into a reduced fatigue at the periphery, as usually observed in this population during high-intensity exercise (Hatzikotoulas et al., 2014; Ratel et al., 2015). In addition, the lower anaerobic capacity and the greater parasympathetic reactivation of the autonomic nervous system early in the recovery period after exercise in prepubertal children could explain the faster readjustment of cardiovascular parameters (Armon et al., 1991; Ohuchi et al., 2000) and the higher removal ability of lactate from the blood compartment $\left(\gamma_{2}\right)$.

\section{Comparison Between Children and Endurance Adult Athletes}

In contrast to untrained adults, prepubertal children displayed the same metabolic profile as well-trained adult endurance athletes. The $\mathrm{P}_{\max }$-to- $\mathrm{PVO}_{2 \max }$ ratio was similar in children and endurance-trained athletes (1.9 vs. 2.1 , respectively), and was consistent with those previously reported in well-trained adult endurance athletes who had $\mathrm{VO}_{2 \max }$ values between 60 and $70 \mathrm{~mL} \cdot \mathrm{min}^{-1} \cdot \mathrm{kg}^{-1}(\sim 2.0$ for Meeuwisse et al., 1992; Hostrup et al., 2016). Furthermore, the relative energy contribution derived from oxidative metabolism during the Wingate test as well as the post-exercise recovery rate of $\mathrm{VO}_{2}$ were similar in children and endurance adult athletes. On this basis, prepubertal children could be considered analogous to welltrained adult endurance athletes from a physiological perspective, 
despite them having a lower work capacity than their older counterparts, i.e., a lower mean power output during the Wingate test (Ratel and Blazevich, 2017). Surprisingly, the results of the present study also showed a faster post-exercise HR recovery rate in prepubertal children than endurance adult athletes. This unexpected result could be ascribed to a greater parasympathetic reactivation of the autonomic nervous system in the early recovery period in prepubertal children than welltrained adult endurance athletes, owing to a greater central cholinergic modulation of HR (Ohuchi et al., 2000). However, further studies comparing the low-frequency and high-frequency components of HR variability in the early recovery period between both populations are required to test this assumption. Furthermore, the results of the present study indicated a lack of difference in $\gamma_{1}$ and a higher $\gamma_{2}$ in children than welltrained adult endurance athletes, suggesting that prepubertal children could have a better capacity to remove lactate from the blood compartment than their older trained counterparts. This difference in $\gamma_{2}$ may be related to the shorter circulation time in children (Cumming, 1978), as evidenced by their faster HR recovery rate in the present study; the faster HR recovery rate, the higher lactate removal ability $\left(\gamma_{2}\right)$ following the Wingate test.

On a more practical level, the similar metabolic profile of prepubertal children and well-trained adult endurance athletes translated into comparable fatigue rates during the Wingate test ( -35.2 vs. $-41.8 \%$, respectively) despite children taking more time to reach their maximal anaerobic power output. This is consistent with experimental data obtained by Hebestreit et al. (1993) and Harbili (2015) who indirectly showed comparable fatigue rates during the Wingate test between prepubertal boys $(-44 \%)$ and professional male road cyclists of Olympic and national levels $(-43 \%)$. Based on these data, it is presumed that the greater reliance on oxidative energy sources and the lower relative anaerobic contribution in well-trained adult endurance athletes (Pesta et al., 2013) translate into a lower peripheral (i.e., muscular) fatigue, as usually observed in prepubertal children compared to untrained adults during repeated maximal voluntary muscle contractions (Hatzikotoulas et al., 2014; Ratel et al., 2015). However, until now the central and peripheral components of neuromuscular fatigue during high-intensity exercise in well-trained adult endurance athletes have only been compared to those of explosive power-trained athletes (Garrandes et al., 2007) and not to untrained adults. Further studies comparing the peripheral and central components of neuromuscular fatigue between prepubertal children, well-trained adult endurance athletes and untrained adults are therefore required to check this assumption.

\section{REFERENCES}

Allen, D. G., Lamb, G. D., and Westerblad, H. (2008). Skeletal muscle fatigue: cellular mechanisms. Physiol. Rev. 88, 287-332. doi: 10.1152/physrev.00015.2007

Armon, Y., Cooper, D. M., Flores, R., Zanconato, S., and Barstow, T. J. (1991). Oxygen uptake dynamics during high-intensity exercise in

\section{CONCLUSION}

The results of the present study showed a comparable net contribution of energy derived from aerobic metabolism during the Wingate test between prepubertal children and welltrained adult endurance athletes. Furthermore, the post-exercise recovery kinetics of oxygen uptake and $\mathrm{HR}$ were respectively similar and faster in prepubertal children than well-trained adult endurance athletes. The removal ability of lactate out of the blood compartment was also higher in children than well-trained adult endurance athletes. These results could explain why the rate and magnitude of fatigue in prepubertal children are similar to welltrained adult endurance athletes and why they recover faster from high-intensity exercise than untrained adults.

\section{PRACTICAL APPLICATIONS}

On a more practical level, the results of the present study suggest that prepubertal children may not have to perform specific training to develop their aerobic metabolic competence. Other strategies might be considered before puberty to improve exercise performance, including entrainment of anaerobic systems and movement technique training to improve mechanical efficiency. In contrast, as the maturational and growth processes have an adverse effect on oxidative energy production in exercising muscle, aerobic training may be a high priority in pubertal and post-pubertal children to maintain their aerobic potential and delay the development of exercise-induced fatigue.

\section{ETHICS STATEMENT}

This study was carried out in accordance with the recommendations of the local Institutional Ethics Review Board. The protocol was approved by the local Institutional Ethics Review Board. All subjects gave written informed consent in accordance with the Declaration of Helsinki.

\section{AUTHOR CONTRIBUTIONS}

All authors contributed to the data analysis and interpretation of the data, drafting, and revising the manuscript, and approved the final version of the manuscript. The original study design was made by $\mathrm{AB}, \mathrm{PB}, \mathrm{AJB}, \mathrm{PD}$, and $\mathrm{SR}$ and discussed with the other authors. $\mathrm{AB}, \mathrm{PB}, \mathrm{EP}$, and $\mathrm{HM}$ performed the data analysis.

\section{ACKNOWLEDGMENTS}

The authors wish to thank the volunteers for their patience, time and effort.

children and adults. J. Appl. Physiol. 70, 841-848. doi: 10.1152/jappl.1991. 70.2 .841

Baraldi, E., Cooper, D. M., Zanconato, S., and Armon, Y. (1991). Heart rate recovery from 1 minute of exercise in children and adults. Pediatr. Res. 29, 575-579. doi: 10.1203/00006450-199106010-00011

Baron, R. (2001). Aerobic and anaerobic power characteristics of off-road cyclists. Med. Sci. Sports Exerc. 33, 1387-1393. doi: 10.1097/00005768-200108000-00022 
Bar-Or, O. (1986). Pathophysiological factors which limit the exercise capacity of the sick child. Med. Sci. Sports Exerc. 18, 276-282. doi: 10.1249/00005768-198606000-00004

Bar-Or, O. (1987). The Wingate anaerobic test. An update on methodology, reliability and validity. Sports Med. 4, 381-394. doi: 10.2165/00007256-198704060-00001

Beneke, R., Hütler, M., Jung, M., and Leithauser, R. M. (2005). Modeling the blood lactate kinetics at maximal short-term exercise conditions in children, adolescents, and adults. J. Appl. Physiol. 99, 499-504. doi: 10.1152/japplphysiol.00062.2005

Beneke, R., Hutler, M., and Leithauser, R. M. (2007). Anaerobic performance and metabolism in boys and male adolescents. Eur. J. Appl. Physiol. 101, 671-677. doi: 10.1007/s00421-007-0546-0

Blimkie, C. J. R., Roche, P., and Bar-Or, O. (1986). "The anaerobic-to-aerobic power ratio in adolescent boys and girls," in Children and Exercise, Vol XII, eds J. Rutenfranz, R. Mocellin and F. Klimt (Champaign, IL: Human Kinetics), 31-37.

Bogdanis, G. C., Nevill, M. E., Boobis, L. H., Lakomy, H. K., and Nevill, A. M. (1995). Recovery of power output and muscle metabolites following $30 \mathrm{~s}$ of maximal sprint cycling in man. J. Physiol. 482(Pt 2), 467-480. doi: 10.1113/jphysiol.1995.sp020533

Carlson, J., and Naughton, G. (1994). Performance characteristics of children using various braking resistances on the wingate anaerobic test. J. Sports Med. Phys. Fitness 34, 362-369.

Cohen, J. (1969). Statistical Power Analysis for the Behavioral Sciences. New York, NY: Academic Press.

Cumming, G. R. (1978). Recirculation times in exercising children. J. Appl. Physiol. Respir. Environ. Exerc. Physiol. 45, 1005-1008. doi: 10.1152/jappl.1978.45.6.1005

De Ste Croix, M. B., Deighan, M. A., Ratel, S., and Armstrong, N. (2009). Age- and sex-associated differences in isokinetic knee muscle endurance between young children and adults. Appl. Physiol. Nutr. Metab. 34, 725-731. doi: 10.1139/H09-064

Dotan, R., Mitchell, C., Cohen, R., Klentrou, P., Gabriel, D., and Falk, B. (2012). Child-adult differences in muscle activation-a review. Pediatr. Exerc. Sci. 24, 2-21. doi: $10.1123 /$ pes.24.1.2

Dotan, R., Ohana, S., Bediz, C., and Falk, B. (2003). Blood lactate disappearance dynamics in boys and men following exercise of similar and dissimilar peak-lactate concentrations. J. Pediatr. Endocrinol. Metab. 16, 419-429. doi: 10.1515/JPEM.2003.16.3.419

Falgairette, G., Bedu, M., Fellmann, N., Van-Praagh, E., and Coudert, J. (1991). Bio-energetic profile in 144 boys aged from 6 to 15 years with special reference to sexual maturation. Eur. J. Appl. Physiol. Occup. Physiol. 62, 151-156. doi: $10.1007 / B F 00643734$

Falk, B., and Bar-Or, O. (1993). Longitudinal changes in peak aerobic and anaerobic mechanical power of circumpubertal boys. Pediatr. Exerc. Sci. 5, 318-331. doi: 10.1123/pes.5.4.318

Garrandes, F., Colson, S. S., Pensini, M., Seynnes, O., and Legros, P. (2007). Neuromuscular fatigue profile in endurance-trained and power-trained athletes. Med. Sci. Sports Exerc. 39, 149-158. doi: $10.1249 / 01 . m s s .0000240322 .00782 . c 9$

Hamley, E. J., and Thomas, V. (1967). Physiological and postural factors in the calibration of the bicycle ergometer. J. Physiol. 191, 55P-56P.

Harbili, S. (2015). The effect of different recovery duration on repeated anaerobic performance in elite cyclists. J. Hum. Kinet. 49, 171-178. doi: 10.1515/hukin-2015-0119

Hatzikotoulas, K., Patikas, D., Ratel, S., Bassa, E., and Kotzamanidis, C. (2014). Central and peripheral fatigability in boys and men during maximal contraction. Med. Sci. Sports Exerc. 46, 1326-1333. doi: 10.1249/MSS.0000000000000239

Hebestreit, H., Mimura, K., and Bar-Or, O. (1993). Recovery of muscle power after high-intensity short-term exercise: comparing boys and men. J. Appl. Physiol. 74, 2875-2880. doi: 10.1152/jappl.1993.74.6.2875

Hornby, T. G., Lewek, M. D., Thompson, C. K., and Heitz, R. (2009). Repeated maximal volitional effort contractions in human spinal cord injury: initial torque increases and reduced fatigue. Neurorehabil. Neural Repair 23, 928-938. doi: 10.1177/1545968309 336147
Hostrup, M., Kalsen, A., Auchenberg, M., Bangsbo, J., and Backer, V. (2016). Effects of acute and 2-week administration of oral salbutamol on exercise performance and muscle strength in athletes. Scand. J. Med. Sci. Sports 26, 8-16. doi: $10.1111 /$ sms. 12298

Jaafar, H., Rouis, M., Attiogbé, E., Vandewalle, H., and Driss, T. (2016). A comparative study between the wingate and force-velocity anaerobic cycling tests: effect of physical fitness. Int. J. Sports Physiol. Perform. 11, 48-54. doi: 10.1123/ijspp.2015-0063

Kappenstein, J., Ferrauti, A., Runkel, B., Fernandez-Fernandez, J., Muller, K., and Zange, J. (2013). Changes in phosphocreatine concentration of skeletal muscle during high-intensity intermittent exercise in children and adults. Eur. J. Appl. Physiol. 113, 2769-2779. doi: 10.1007/s00421-013-2712-x

Lazaridis, S., Patikas, D. A., Bassa, E., Tsatalas, T., Hatzikotoulas, K., Ftikas, C., et al. (2018). The acute effects of an intense stretch-shortening cycle fatigue protocol on the neuromechanical parameters of lower limbs in men and prepubescent boys. J. Sports Sci. 36, 131-139. doi: 10.1080/02640414.2017.1287932

Lexell, J., Sjostrom, M., Nordlund, A. S., and Taylor, C. C. (1992). Growth and development of human muscle: a quantitative morphological study of whole vastus lateralis from childhood to adult age. Muscle Nerve 15, 404-409. doi: $10.1002 /$ mus. 880150323

Louis, J., Hausswirth, C., Easthope, C., and Brisswalter, J. (2012). Strength training improves cycling efficiency in master endurance athletes. Eur. J. Appl. Physiol. 112, 631-640. doi: 10.1007/s00421-011-2013-1

Meeuwisse, W. H., Mckenzie, D. C., Hopkins, S. R., and Road, J. D. (1992). The effect of salbutamol on performance in elite nonasthmatic athletes. Med. Sci. Sports Exerc. 24, 1161-1166. doi: 10.1249/00005768-199210000-00015

Mercier, B., Granier, P., Mercier, J., Trouquet, J., and Prefaut, C. (1993). Anaerobic and aerobic components during arm-crank exercise in sprint and middle-distance swimmers. Eur. J. Appl. Physiol. Occup. Physiol. 66, 461-466. doi: 10.1007/BF00599622

Mirwald, R. L., Baxter-Jones, A. D., Bailey, D. A., and Beunen, G. P. (2002). An assessment of maturity from anthropometric measurements. Med. Sci. Sports Exerc. 34, 689-694. doi: 10.1097/00005768-200204000-00020

Noakes, T. D., St Clair Gibson, A., and Lambert, E. V. (2005). From catastrophe to complexity: a novel model of integrative central neural regulation of effort and fatigue during exercise in humans: summary and conclusions. Br. J. Sports Med. 39, 120-124. doi: 10.1136/bjsm.2003.010330

Nordlund, M. M., Thorstensson, A., and Cresswell, A. G. (2004). Central and peripheral contributions to fatigue in relation to level of activation during repeated maximal voluntary isometric plantar flexions. J. Appl. Physiol. 96, 218-225. doi: 10.1152/japplphysiol.00650.2003

Ohuchi, H., Suzuki, H., Yasuda, K., Arakaki, Y., Echigo, S., and Kamiya, T. (2000). Heart rate recovery after exercise and cardiac autonomic nervous activity in children. Pediatr. Res. 47, 329-335. doi: 10.1203/00006450-20000300000008

Pesta, D., Paschke, V., Hoppel, F., Kobel, C., Kremser, C., Esterhammer, R., et al. (2013). Different metabolic responses during incremental exercise assessed by localized 31P MRS in sprint and endurance athletes and untrained individuals. Int. J. Sports Med. 34, 669-675. doi: 10.1055/s-0032-1327648

Ratel, S., and Blazevich, A. J. (2017). Are prepubertal children metabolically comparable to well-trained adult endurance athletes? Sports Med. 47, 1477-1485, doi: 10.1007/s40279-016-0671-1

Ratel, S., Duche, P., Hennegrave, A., Van Praagh, E., and Bedu, M. (2002). Acidbase balance during repeated cycling sprints in boys and men. J. Appl. Physiol. 92, 479-485. doi: 10.1152/japplphysiol.00495.2001

Ratel, S., Kluka, V., Vicencio, S. G., Jegu, A. G., Cardenoux, C., Morio, C., et al. (2015). Insights into the mechanisms of neuromuscular fatigue in boys and men. Med. Sci. Sports Exerc. 47, 2319-2328. doi: 10.1249 /MSS.0000000000000697

Ratel, S., Tonson, A., Le Fur, Y., Cozzone, P., and Bendahan, D. (2008). Comparative analysis of skeletal muscle oxidative capacity in children and adults: a 31P-MRS study. Appl. Physiol. Nutr. Metab. 33, 720-727. doi: $10.1139 / \mathrm{H} 08-039$

Ratel, S., Williams, C. A., Oliver, J., and Armstrong, N. (2004). Effects of age and mode of exercise on power output profiles during repeated sprints. Eur. J. Appl. Physiol. 92, 204-210. doi: 10.1007/s00421-004-1081-x

Rowland, T. W., Staab, J. S., Unnithan, V. B., Rambusch, J. M., and Siconolfi, S. F. (1990). Mechanical efficiency during cycling in prepubertal 
and adult males. Int. J. Sports Med. 11, 452-455. doi: 10.1055/s-20071024836

Shargal, E., Kislev-Cohen, R., Zigel, L., Epstein, S., Pilz-Burstein, R., and Tenenbaum, G. (2015). Age-related maximal heart rate: examination and refinement of prediction equations. J. Sports Med. Phys. Fitness 55, 1207-1218.

Short, K. R., and Sedlock, D. A. (1997). Excess postexercise oxygen consumption and recovery rate in trained and untrained subjects. J. Appl. Physiol. 83, 153-159. doi: 10.1152/jappl.1997.83.1.153

Slaughter, M. H., Lohman, T. G., Boileau, R. A., Horswill, C. A., Stillman, R. J., Van Loan, M. D., et al. (1988). Skinfold equations for estimation of body fatness in children and youth. Hum. Biol. 60, 709-723.

Streckis, V., Skurvydas, A., and Ratkevicius, A. (2007). Children are more susceptible to central fatigue than adults. Muscle Nerve 36, 357-363. doi: 10.1002/mus.20816

Tonson, A., Ratel, S., Le Fur, Y., Vilmen, C., Cozzone, P. J., and Bendahan, D. (2010). Muscle energetics changes throughout maturation: a quantitative 31PMRS analysis. J. Appl. Physiol. 109, 1769-1778. doi: 10.1152/japplphysiol.014 23.2009
Williams, J. G., Eston, R., and Furlong, B. (1994). CERT: a perceived exertion scale for young children. Percept. Mot. Skills 79, 1451-1458. doi: 10.2466/pms.1994.79.3f.1451

Zouloumian, P., and Freund, H. (1981). Lactate after exercise in Man: II. Mathematical model. Eur. J. Appl. Physiol. Occup. Physiol. 46, 135-147. doi: $10.1007 / \mathrm{BF} 00428866$

Conflict of Interest Statement: The authors declare that the research was conducted in the absence of any commercial or financial relationships that could be construed as a potential conflict of interest.

Copyright (C) 2018 Birat, Bourdier, Piponnier, Blazevich, Maciejewski, Duché and Ratel. This is an open-access article distributed under the terms of the Creative Commons Attribution License (CC BY). The use, distribution or reproduction in other forums is permitted, provided the original author(s) and the copyright owner are credited and that the original publication in this journal is cited, in accordance with accepted academic practice. No use, distribution or reproduction is permitted which does not comply with these terms. 